\title{
ESCOLA LIVRE PARA EDUCADORES PROFISSIONAIS E LEIGOS
}

\author{
FREE SCHOOL FOR PROFESSIONAL AND LAY EDUCATORS
}

\section{ESCUELA LIBRE PARA EDUCADORES PROFESIONALES Y LAICOS}

\author{
Carla A. Barreto \\ Doutora em Educação Escolar - FCLAr \\ Faculdade Santa Bárbara - FAESB, Diretora Acadêmica. \\ E-mail: academica@faesb.edu.br \\ Alessandra de Carvalho Faria \\ Mestre em Educação Escolar - FCLAr \\ Secretaria Municipal de Educação de Ribeirão Preto. \\ E-mail: alessandrafaria@hotmail.com
}

\section{RESUMO}

Pretende-se nesta comunicação apresentar as atividades desenvolvidas através do projeto de extensão intitulado Escola Livre para educadores profissionais e leigos; o projeto foi vinculado a um Grupo de Pesquisa atuante na Educação Infantil e pertence à FCLAr/Unesp/SP/Brasil. A proposta formativa do grupo teve como diretriz garantir o entendimento e reconhecimento da necessidade de formação, orientação e sensibilização para projetar espaços de integração entre contextos de instituição de educação infantil e famílias na responsabilidade partilhada na educação da infância. A pesquisa aqui apresentada compõe o relato das pesquisadoras envolvidas, a partir das técnicas da pesquisa e abordagem qualitativa.

Palavras-chave: Educação infantil. Formação de educadores. Escola Livre.

\begin{abstract}
The purpose of this communication is to present the activities developed through the extension project titled Free School for professional and lay educators, the projeton was linked to a Research Group active in Early Childhood Education and belongs to FCLAr / Unesp / SP / Brasil. The formative proposal of the group had as guideline to guarantee the understanding and recognition of the need for formation, orientation and sensitization to design spaces of integration between contexts of institution of children education and families in shared responsibility in the education of childhood. The research presented here composes the report of the researchers involved, based on the research techniques qualitative.
\end{abstract}

Keywords: Child education. Training of educators. Free School.

91

RELEDUC | ISE | v. 2 | n. 1 | fev. 2019 


\section{RESUMEN}

Se pretende en esta comunicación presentar las actividades desarrolladas a través del proyecto de extensión titulado Escuela Libre para educadores profesionales y laicos, el proyecto fue vinculado a un Grupo de Investigación actuante en la Educación Infantil y pertenece a la FCLAr / Unesp / SP / Brasil. La propuesta formativa del grupo tuvo como directriz garantizar el entendimiento y reconocimiento de la necesidad de formación, orientación y sensibilización para proyectar espacios de integración entre contextos de institución de educación infantil y familias en la responsabilidad compartida en la educación de la infancia. La investigación aquí presentada compone el relato de las investigadoras involucradas, a partir de las técnicas de la investigación y abordaje cualitativo.

Palabras clave: Educación infantil. Formación de educadores. Escuela Libre.

\section{INTRODUÇÃO}

Como anunciado, no resumo desta comunicação, pretendemos apresentar as atividades desenvolvidas através do projeto de extensão intitulado Escola Livre para educadores profissionais e leigos, o qual se vincula ao Grupo de Pesquisa Educação Infantil: aprendizagem e desenvolvimento profissional em contextos integrados junto à Universidade Estadual Paulista - Unesp, campus de Araraquara, São Paulo, Brasil. Para tanto, faz-se necessário delinear a atuação desta equipe de pesquisa para podermos realizar tal empreitada, uma vez que são das atividades diversas da equipe que surgiu a proposta da Escola Livre.

A equipe está composta por profissionais de diferentes áreas, os quais congregam diferentes perspectivas de fundamentos e experiências, a atuação destes profissionais enquanto horizonte de pesquisa tem como objetivo central o diagnóstico e implementação de critérios fundamentais para a melhoria da qualidade do atendimento à infância. Além, de articular estudos sobre a profissionalidade do educador infantil aos estudantes/estagiários do curso de Pedagogia da referida instituição, bem como iniciação à pesquisa.

Das pesquisas realizadas sobre a qualidade no atendimento à infância, bem como dos estudos sobre profissionalidade docente do educador infantil foi se delineando junto ao grupo a perspectiva da horizontalidade das relações como instrumental fundamental, essencial para garantirmos e alcançarmos situação de igualdade, uma vez que essa dinâmica instituída 
permite que todos sejam aprendizes e experientes na vivência de papéis, funções e compromissos com a infância.

Dessa forma, foi se entendendo e reconhecendo a necessidade de formação, orientação e sensibilização, entre os diversos atores educativos, para que se possam projetar espaços de integração de contextos entre instituição de educação infantil e famílias na responsabilidade partilhada na educação da infância; para que se possam superar conceitos ultrapassados, culturas pedagógicas de pouca sustentação e fundamentação; para que se possa difundir conhecimento sobre o desenvolvimento infantil, o papel das instituições, de seus profissionais e a finalidade educacional do atendimento educacional oferecido às crianças menores de 6 anos, bem como os ganhos da infância com o investimento educacional é que esta sendo proposta uma iniciativa de Escola Livre para Educadores Profissionais e Leigos.

“[...] a essência da proposta consiste em atrair, chamar para diálogo os pais, profissionais, estudiosos, os atores educativos que compõem diferentes instituições que partilham e compartilham do cuidado e da educação de crianças" (BARRETO; ANGOTTI, 2009, p. 152). Assim,

A escola Livre é entendida e foi desenhada como possiblidade de criação de um espaço aberto, livre sem formalidades destinado a participação de adultos interessados nas questões relacionadas à infância e a educação de crianças de 0 até 6 anos de idade (BARRETO; ANGOTTI, 2009, p. 152).

O princípio básico da Escola Livre consiste na vivência com professoras e pais dos propósitos e práticas que se quer sejam experienciados pela, junto e com a criança. Ou seja, se a atividade e participação da criança é defendida como condição de desenvolvimento de sua autonomia, o mesmo princípio será válido para a formação de adultos que convivem e atuam na educação da infância, a garantir o desenvolvimento integral da criança, bem como todos os seus direitos garantidos pela constituição

$\mathrm{O}$ intuito desta proposta reside na necessidade do estabelecimento de diálogos para a estruturação de partilhas de responsabilidade na educação da criança menor de 6 anos de idade, definida por projeto pedagógico coletivo, que possa consignar os ideais comuns e procedimentos consentidos na busca pelo desenvolvimento integral da criança e num ideal de sociedade que se queira alcançar. 
Enquanto grupo de pesquisa, constituído de estudiosos do tema, pensamos na necessidade de publicizar a temática, isto é, torná-la inteligível, presente no cotidiano dos pais dessas crianças, promover o diálogo com os profissionais e os pais, entre os profissionais e entre nós estudiosos, uma vez que o discurso bate na tônica da qualidade, da frequência que deve ser respeitada, mas será que o pai, a sociedade em geral entende o real significado dessa etapa de vida, desse momento singular da infância? Discutir essas questões esse é o objetivo mister da Escola Livre e as atividades propostas volveram e foram desenvolvidas com vistas a alcançar essa meta.

A partir de 2007 constituímos a Escola Livre como forma de estruturar e formalizar um espaço de discussão sobre os direitos atinentes a primeira infância para além dos muros institucionais e, dessa forma, constituir-se em um laboratório de formação contínua e continuada pautada na horizontalização das relações com vistas ao favorecimento da integração de contextos.

A Escola Livre toma como recurso metodológico o diálogo que prima pela horizontalidade das relações independentemente de ser coordenado por pesquisadores, representantes dos muros institucionais da Universidade, mas propõem a troca de conhecimento, como já anunciado, entre os membros da comunidade, os pais, os profissionais da educação, para que o conhecimento possa ser trocado, experienciado e vivenciado em sua amplitude e grandeza maior, para que todos os atores envolvidos sintam-se pertencentes da construção da sua identidade, da sua cultura, da sua autonomia, e por consequência, sintam a pertença social e em posse desse valioso instrumental reivindiquem - se necessário e preciso for - com consciência as questões referentes à Educação Infantil, isto é sua importância, sua necessidade na formação integral do homem.

Consideramos que a realidade social não é exterior e nem se opõe aos indivíduos, e que a motivação, é a forma pela qual podemos entender como a ordem social e as normas são concretizadas pelos indivíduos, por isso, buscamos articular um projeto que visou publicizar e discutir o sentido da ação social e política no tocante à infância. ((BARRETO; ANGOTTI, 2012, p. 179).

Percebemos, que essa prática de diálogo, base da Escola Livre carrega a ação reflexiva, a práxis, mas o mais importante são as relações não hierarquizadas e sim RELEDUC | ISE | v. 2 | n. 1 | fev. 2019 
horizontalizadas, a comunhão que é formada em cada atividade proposta, o qual é fundamental para o estabelecimento de responsabilidade e co-responsabilidade nas ações, tornar-se sujeito essa é a maior ambição da Escola Livre.

\section{AS AÇÕES DESENVOLVIDAS PELA ESCOLA LIVRE E SEU COMPROMISSO SOCIAL}

A dinâmica metodológica em um primeiro momento foi determinada por encontros mensais aos sábados para que não existisse nenhum impedimento funcional para a participação dos envolvidos.

O primeiro encontro orientou-se pela temática "A infância que temos, a infância que tivemos e quais projetos temos para amanhã", na ocasião tivemos a presença de pais, professores, estudantes, na dinâmica foi apresenta a proposta de Escola Livre e feita uma atividade de sensibilização a partir de formas variadas de apresentar um breve relato sobre o tema, o qual poderia ser por meio da dramatização, colagem, painel. Os presentes se mostraram extremamente envolvidos com a atividade e relataram as lembranças da infância pretérita e as possibilidades para projetarmos o futuro.

A partir de 2009 os encontros trataram os temas por meio de oficinas de trabalho teórico-práticas, ministradas pelos membros da equipe de pesquisa, de forma a promover a experiência com a integração, a sensibilização dos atores educativos responsáveis profissionalmente ou não com a educação da criança. Com o desenvolvimento das oficinas e o próprio devir do projeto o mesmo foi reestruturado e os encontros passaram a ser programados mensalmente.

A Escola Livre iniciou com um evento na praça do município de Araraquara chamado “Educação Infantil não é carnaval, mas também está nas ruas", com o objetivo de divulgar a Educação Infantil, crianças e pais, como interessados foram convidados a participarem de diversas atividades na praça, como pintura a guache, jogos, teatro, outros. O evento também convidou pessoas interessadas a participarem conosco das reuniões da Escola Livre, e continuarem os diálogos sobre a Educação Infantil.

$$
\text { RELEDUC | ISE | v. } 2 \text { | n. } 1 \text { | fev. } 2019
$$


Neste ano a Escola Livre apresentou-se no formato de palestras ocorridas aos sábados mensalmente na universidade, sendo a primeira ministrada pela pesquisadora do grupo e diretora de escola com o tema "Visão de uma diretora de instituição pública de Educação Infantil", do município de Araraquara.

A palestra visou demonstrar como funciona a estrutura, rotina e atividades pedagógicas com as crianças na instituição de Educação Infantil. A diretora expôs a forma de trabalho pedagógico desenvolvido na escola, a divisão das turmas de acordo com a faixa etária, o quadro de funcionários, e outras informações pertinentes à escola como também à rede educacional municipal.

A diretora ressaltou que a creche não é cabideiro de criança, mas um local de aprendizado para que esta possa aprender e se desenvolver integralmente. Dificuldades foram também discutidas na ocasião como: espaço físico, proporção adulto versus criança, quadro de funcionários, formação inicial docente, jornada de trabalho versus remuneração, participação da família, políticas públicas versus conhecimento científico, outros.

Em outra palestra, tivemos a explanação da diretora do CCI (Centro de Convivência Infantil) creche da Universidade Estadual Paulista "Júlio de Mesquita Filho", no mesmo formato da exposição anterior. Sendo assim, pudemos analisar outra forma de trabalho pedagógico na Educação Infantil, com outras características, rotinas, e objetivos, como também atendendo um grupo de crianças diferenciado em relação ao da comunidade atendida da instituição mencionada na palestra anterior.

Em seguida, houve a palestra da socióloga e pesquisadora do grupo abordando o tema sobre "O que é política pública social?". Falando-nos sobre o que são políticas sociais, de que forma são postas pelo Estado e como atendem as diferentes demandas sociais existentes. E como estas políticas podem ser direcionadas à Educação Infantil.

Após este ciclo de palestras, aconteceu uma reunião de análise das atividades da Escola Livre referente aos dois últimos anos. O grupo decidiu-se mudar para uma nova formatação que pudesse buscar novas estratégias com atividades a contribuir para a publicização da Educação Infantil, a serem estabelecidas nas próximas reuniões.

RELEDUC | ISE | v. 2 | n. 1 | fev. 2019 
Em decorrência do COPEDI (2009) ${ }^{1}$, tivemos uma reunião da Escola Livre Em decorrência do COPEDI (2009) $)^{2}$, tivemos uma reunião da Escola Livre para a apresentação dos trabalhos apresentados neste congresso, primeiramente com a fala de uma das pesquisadoras com o tema "Escola Livre: um espaço coletivo de produção cultural para a infância”. O trabalho teve por objetivo fazer um panorama das atividades da Escola Livre até aqui, como um espaço de ação e reflexão a respeito do que se foi falado e discutido sobre cultura da infância. E de como resgatar a criação do adulto sobre a infância, utilizando-se da vivência das diferentes linguagens.

Para tanto, foram citados autores que tratam do processo de criação, criação e arte, e o elemento lúdico no processo de criação da criança. Em seguida, foi apresentado o trabalho da de uma pesquisadora do grupo com o título "Mobilização e Organização dos Profissionais de Educação Infantil: representações de professoras", tratando da parceria da comunidade, pais e Educação Infantil, outro trabalho foi "Escola Livre: espaço para ação e reflexão". Em nossa última reunião do ano planejamos o cronograma do ano seguinte, já pensando em atividades a serem realizadas em praça pública para mobilizar a comunidade, e outras temáticas que poderiam ser discutidas nas próximas reuniões.

No ano seguinte, as atividades mensais da Escola Livre foram temporariamente suspensas, devido à mobilização do grupo como um todo (GPEI), para o planejamento do Congresso de Educação Infantil que ocorreu em 2010 com o nome "A educação informal constituindo a formalidade de atendimento na primeira infância", que teve por finalidade discutir o reconhecimento e valorização de todas as pessoas que atuam na educação infantil, em busca de formação nos cursos de pedagogia para uma atuação com fundamentação teórico-metodológica, e de um atendimento com qualidade que garanta o desenvolvimento integral da criança, que já são direitos adquiridos da primeira infância.

Em 2011, a Escola Livre volta com outro formato conforme o que já havíamos pensado no final de 2009, após discussão e reflexão das últimas atividades ocorridas,

\footnotetext{
${ }^{1}$ COPEDI - Congresso Paulista de Educação Infantil - membros do nosso grupo de pesquisa (GPEI) estiveram neste evento apresentando trabalhos.
} 
verificou que ficaram inviáveis as reuniões mensais, pela falta de participação de mais pessoas, ficando restrito somente ao envolvimento do nosso grupo. Assim, as atividades foram repensadas e tomaram outra direção considerando as necessidades que foram apontadas e, portanto, tínhamos que concentrar ações mais impactantes. As atividades da Escola Livre tiveram como finalidade publicizar a Educação Infantil e valorizar a infância com atendimento específico em diálogos horizontais, para que todos os envolvidos (professores, pais, pedagogos em formação, responsáveis pelas crianças e demais interessados) consigam estabelecer e entender diálogos entre si sobre a importância do atendimento educacional à primeira infância.

Foram realizadas atividades em especial a publicizar a Educação e em especial da Educação Infantil, sua finalidade, compromisso e exigências metodológicas, como por ex: o brincar e as diferentes linguagens como elementos favorecedores do desenvolvimento integral da criança. E a Escola Livre teve um projeto intitulado "Escola Livre: a infầncia e o brincar", atividades de experimentação sobre o brincar realizadas junto à cantina da FCL/UNESP/CAr envolvendo alunos, funcionários e professores, publicização junto à comunidade - UNIARA e comunidade em geral, e também assunto direcionados à legislação e a importância do brincar, e direitos da criança.

Em 2012, a Escola Livre efetivou-se com outro projeto, ainda dentro da temática de publicização da Educação Infantil, chamado "Escola Livre: experimentando a Educação Infantil”, não somente relacionado à extensão, mas também ligado à pesquisa e formação.

Primeiramente houve uma discussão e planejamento de como efetivamente ocorreria o projeto, e foi decidido que este seria realizado em duas instituições públicas no município de Araraquara, com o objetivo de publicizar a Educação Infantil. Durante um mês antes do evento, as estagiárias do grupo buscaram um processo de aproximação junto aos pais e responsáveis no sentido de trazê-los a uma discussão sobre o que entendem e como entendem a educação de seu filho, sobretudo a oferecida de maneira profissional/ intencional em instituições específicas, chamado de "processo de sedução", utilizando de um procedimento de indagação, as estagiárias fizeram algumas perguntas no decurso de mês de maio para inquietar os atores responsáveis por filhos ou crianças menores de seis anos (ANGOTTI, MASCIOLI, 2012).

$$
\text { RELEDUC | ISE | v. } 2 \text { | n. } 1 \text { | fev. } 2019
$$


O dia do evento é o momento de "experimentação", em que a atividade ocorreu na instituição envolvendo todos os atores educativos, responsáveis da família e da instituição das crianças. Em um primeiro momento, as respostas feitas ao longo do processo de sedução e inquietação foram respondidas em situação de diálogo explicitador ou esclarecedor. Em seguida, houve um procedimento de explicitação sobre a metodologia utilizada na EI e suas contribuições para o desenvolvimento infantil. Na sequência, a experimentação de adultos com as crianças de atividade que envolva linguagens utilizadas para prover o desenvolvimento infantil, de forma a "comprovar" pelo experimento ao adulto da importância e da riqueza da utilização das mesmas, sobretudo da linguagem lúdica que pode envolver várias outras, que aconteceu na forma da Atividade do laranjal.

Esta atividade consistiu de uma história contada de um percurso que haveria de ser seguido por uma floresta dos pais com os filhos pela escola, em que ambos enfrentariam desafios que foram vivenciados de forma lúdica, como imaginar de estar se equilibrando por uma corda, passar por um rio, observar pássaros, até que estes pudessem encontrar o "Laranjal", e foram surpreendidos por animais (membros do grupo caracterizados por máscaras), que tiveram de ser espantado pelo o uso de instrumentos confeccionados por garrafas pets, a fim de o barulho assustá-los, e na volta do percurso, para surpresa de todos, estes foram recebidos com um lanche pelos mesmos animais. Na verdade, a atividade consistiu na experimentação dos adultos da imaginação, criação, do lúdico, e de tantas outras expressões que puderam traduzir num curto momento a importância do trabalho na Educação Infantil. Finalizando a atividade e o evento, houve o lanche com o término da Atividade do laranjal. Conforme Angotti e Mascioli (2012), na atividade “[...] adultos e crianças estarão em atividade lúdica que envolverá a discriminação de sons, a realização de diferentes movimentos, exigirá o espírito de colaboração, a imaginação e o encantamento [...]”.

\section{CONSIDERAÇÕES FINAIS}

A ideia fundamental da Escola Livre era propiciar aos educadores profissionais e leigos a vivência teórica e prática do que está sendo proposto em termos de educação infantil 
que tenha por finalidade o desenvolvimento integral de nossas crianças. Os adultos são colocados na condição de vivência do que a criança vive ou deveria viver nas unidades educacionais, sentindo, percebendo, elaborando e expressando entendimento sobre os compromissos e práticas a serem realizados no processo de formação da infância.

A experiencia permitiu contribuir com a ampliação e visibilidade da área epistêmica, além das pesquisas e demais projetos de extensão desenvolvidos em outros momentos pelo grupo foi formalizar a ideia de um espaço privilegiado de discussão e formação, um laboratório para experimentarmos, vivenciarmos e discutirmos nossa prática".

Assim, o projeto de extensão intitulado "Escola Livre para educadores profissionais e leigos", buscou trazer para discussão com os pais, com os educadores a Educação Infantil como campo especifico de conhecimento, o qual integra o campo da política educacional para além da dimensão do cuidar, na consequente efetivação do educar, trajetória que foi favorecida pela compreensão sobre os processos de desenvolvimento das crianças. Entende-se que o citado avanço ocorreu apenas no campo formal no conjunto de instrumentos legais que passaram a compor o entendimento sobre a infância, o ser criança e seus direitos, mas não em melhorias significativas para a efetivação das práticas de atendimento educacional.

A Escola Livre foi um espaço aberto, livre, sem formalidades destinado à participação de adultos interessados nas questões relacionadas à infância e a educação de crianças de zero até seis anos de idade. O objetivo da equipe era chamar a atenção do cidadão para assumir com conhecimento e responsabilidade os assuntos relacionados à temática, em como difundir a importância de se viver e experimentar a infância e a educação com suas peculiaridades e singularidades. Todo encontro realizado primou o diálogo horizontalizado efetivado em encontros mensais abertos a todos os interessados em conhecer, discutir, analisar e tomar posições em relação à defesa da infância e da educação infantil. A equipe entendia que o princípio básico norteador dos encontros consiste na vivência com e entre professores, pais e interessados dos propósitos e práticas que se quer sejam experienciados pela, junto e com a criança.

Os resultados demonstraram que as interações e diálogos vivenciados em nossos encontros propiciaram reflexão sobre o papel dos adultos na construção de oportunidades para a infância e para que as crianças sejam realmente reconhecidas como cidadãs de direito.

$$
\text { RELEDUC | ISE | v. } 2 \text { | n. } 1 \text { | fev. } 2019
$$


Contribuição em relação à educação como campo epistêmico foi formalizar a ideia de uma Escola Livre como um espaço privilegiado de discussão e formação.

O desconhecimento de experiências desta natureza no Brasil torna a iniciativa inovadora e exigente de considerar entre outros pontos os seguintes: a) a pouca divulgação do conceito e da importância do atendimento educacional às crianças menores de 6 anos de idade; b) -a pouca participação de pais e o desconhecimento das condições de formação de seus filhos devido aos compromissos com a realização pessoal e profissional que os afastaram da dinâmica familiar e das responsabilidades com a educação de seus filhos; c) -o interesse das educadoras infantis com questões que respondam de maneira mais imediata às necessidades de proposição de atividades práticas, não considerando muitas vezes a necessária reflexão, planejamento e fundamentação do que se realiza junto a e pela criança.

Cabe salientar que a participação não revela necessariamente compromissos de muitos, nem a constância nas convicções que possam manter a frequência nas atividades e propósitos defendidos, o que causa a certeza de que ainda há muito que fazer em prol da cidadania plena e dos direitos constitucionais, sobretudo os relativos à educação da primeira infância.

\section{REFERÊNCIAS}

ANGOTTI, Maristela; BARRETO, Carla A. Escola Livre para Educadores Profissionais e Leigos: um projeto de integração de contextos em favor da infância e da qualidade na educação infantil. In: Angotti, Maristela.(org.) Educação Infantil: da condição de direito à condição de qualidade no atendimento. Campinas: editora Alínea, 2009.

ANGOTTI, Maristela; BARRETO, Carla A. Perspectivas de investimento na formação docente: uma realidade em processo. In: Angotti, Maristela. (Org.), A Educação Infantil em diálogos, Campinas: editora Alínea, 2012.

ANGOTTI, Maristela; BARRETO, Carla Alessandra. Escola livre para educadores profissionais e leigos: um espaço de desafios. CONGRESSO DE EXTENSÃO UNIVERSITÁRIA, 5., 2019, Águas de Lindólia. Anais... São Paulo: PROEX; UNESP, 2009, p. 226 Disponível em: 〈http://hdl.handle.net/11449/147607>.

ANGOTTI, Maristela; MASCIOLI, Suselaine Zaniolo. Formação do professor para a Educação Infantil em contexto de múltiplas articulações, integrações e experimentações. In:

$$
\text { RELEDUC | ISE | v. } 2 \text { | n. } 1 \text { | fev. } 2019
$$


Programa e Resumos de Anais do VI COPEDI - Congresso Paulista de Educação Infantil e II Congresso Internacional de Educação Infantil | "Educação Infantil subvertendo ordens? Política, imaginação e fantasia". São Paulo, 2012. 